\title{
Numerical Simulation of Single-Point Mount PZT-Interface for Admittance-Based Anchor Force Monitoring
}

\author{
Trung-Hau Nguyen ${ }^{1,2}$, Thi Tuong Vy Phan ${ }^{3,4} \mathbb{D}$, Thanh-Cao Le ${ }^{2,5}$, Duc-Duy Ho ${ }^{2,5, *(\mathbb{D})}$ \\ and Thanh-Canh Huynh 3,6,*(D)
}

1 Faculty of Applied Science, Ho Chi Minh City University of Technology (HCMUT), 268 Ly Thuong Kiet, District 10, Ho Chi Minh City 700000, Vietnam; haunguyen85@hcmut.edu.vn

2 Vietnam National University Ho Chi Minh City (VNU-HCM), Linh Trung Ward, Thu Duc District, Ho Chi Minh City 700000, Vietnam; 1880698@hcmut.edu.vn

3 Institute of Research and Development, Duy Tan University, Danang 550000, Vietnam; phanttuongvy4@duytan.edu.vn

4 Faculty of Environmental and Chemical Engineering, Duy Tan University, Danang 550000, Vietnam

5 Faculty of Civil Engineering, Ho Chi Minh City University of Technology (HCMUT), 268 Ly Thuong Kiet, District 10, Ho Chi Minh City 700000, Vietnam

6 Faculty of Civil Engineering, Duy Tan University, Danang 550000, Vietnam

* Correspondence: hoducduy@hcmut.edu.vn (D.-D.H.); huynhthanhcanh@duytan.edu.vn (T.-C.H.)

Citation: Nguyen, T.-H.; Phan, T.T.V.; Le, T.-C.; Ho, D.-D.; Huynh, T.-C.

Numerical Simulation of Single-Point Mount PZT-Interface for AdmittanceBased Anchor Force Monitoring. Buildings 2021, 11, 550. https:// doi.org/10.3390/buildings11110550

Academic Editors: Giuseppina Uva and Sergio Ruggieri

Received: 4 November 2021

Accepted: 15 November 2021

Published: 16 November 2021

Publisher's Note: MDPI stays neutral with regard to jurisdictional claims in published maps and institutional affiliations.

Copyright: (c) 2021 by the authors. Licensee MDPI, Basel, Switzerland. This article is an open access article distributed under the terms and conditions of the Creative Commons Attribution (CC BY) license (https:// creativecommons.org/licenses/by/ $4.0 /)$.

\begin{abstract}
This study investigates the dynamic characteristics of a smart PZT interface mounted on a prestressed anchorage to verify the numerical feasibility of the admittance-based anchor force monitoring technique. Firstly, the admittance-based anchor force monitoring technique through a single-mount PZT interface is outlined. The admittance response of the PZT interface-anchorage system is theoretically derived to show the proof-of-concept of the technique for anchor force monitoring. Secondly, a finite element model corresponding to a well-established experimental model in the literature is constructed. The effect of anchor force is equivalently treated by the contact stiffness and damping parameters at the bottom surface of the anchorage. Thirdly, the admittance and the impedance responses are numerically analyzed and compared with the experimental data to evaluate the accuracy of the numerical modelling technique. Fourthly, the local dynamics of the PZT interface are analyzed by modal analysis to determine vibration modes that are sensitive to the change in the contact stiffness (i.e., representing the anchor force). Finally, the admittance responses corresponding to the sensitive vibration modes are numerically analyzed under the change in the contact stiffness. The frequency shift and the admittance change are quantified by statistical damage indices to verify the numerical feasibility of the anchor force monitoring technique via the smart PZT interface. The study is expected to provide a reference numerical model for the design of the single-point mount PZT interface.
\end{abstract}

Keywords: piezoelectric sensor; admittance method; dynamic characteristics; PZT interface; finite element model; anchor force; single-point mount technique

\section{Introduction}

In the past decades, the requirement of structural safety and reliability has increasingly demanded the development of low-cost and online structural health monitoring (SHM) systems for modern complex structures. Among various SHM and damage identification techniques, the admittance-based method has attracted significant attention from both academic and industrial communities and has been successfully applied to various civil engineering structures [1-5]. The technique utilizes an inexpensive piezoelectric transducer (such as PZT) to obtain the admittance signature from a host structure, which is sensitive to a structural change. The admittance response in a high-frequency band with multiple resonances is often used to enhance the detectability of minor structural damage [6]. The 
merits of the admittance-based technique include the cost-effectiveness, the ability to detect a wide range of multi-scale structural damage, the suitability for continuous online SHM, and the easy practical implementation [7].

Traditionally, the piezoelectric transducer is directly attached to the monitored region on a host structure through a bonding layer. However, an issue with the direct attachment is the occurrence of potential weak resonances that could result in difficulties in optimizing the damage-sensitive frequency band in damage detection [8-10]. In some situations, the optimal frequency band could be higher than $100 \mathrm{kHz}$, which is over the measurement capability of currently available low-cost and compact impedance analyzers [11-14]. Research attempts have been conducted to enhance the sensitivity of the admittance signatures to damage and to reduce the demand for high-cost and bulky instruments. The general idea is to design compact piezoelectric devices that are equipped with PZT patches. For example, smart piezoelectric aggregates were proposed to monitor the structural condition of concrete members [15-17], piezoelectric-based smart strands for tension force monitoring [18,19], smart piezoelectric transducers to monitor corrosion occurrence [20], and smart piezoelectric washers to detect preload changes in a bolted joint $[13,21]$.

The prestressing technique has been commonly used to enhance the load-bearing capacity of civil infrastructures. Along with the continuous increasing use of prestressed members, the loss of prestress force has received significant interest from engineers, researchers, and inspection and maintenance crews. A significant drop of the designed prestress force could lead to the reduced load-bearing capacity of the prestressed structure, threatening its safety and serviceability. Due to its distinct merits, the admittance-based technique has been applied to monitor the prestress level in prestressed structures. The previous study showed that the electromechanical impedance (i.e., an inverse of the admittance) of the PZT-driven anchorage was sensitive to prestress force [9]. The smart washer concept was also developed for assessing the prestress-loss in a prestressed girder using wireless low-cost impedance analyzers [13]. In the past years, the concept of the mountable PZT interface was proposed to monitor existing prestressed anchorages [22]. The proposed interface can be easily designed to achieve strong resonances in a frequency band lower than $100 \mathrm{kHz}$, thus enabling the adaptability to currently available low-cost wireless impedance analyzers $[19,23]$.

However, the initial prototype of the mountable PZT interface uses the two-point mount technique, which could cause inconveniences during installation and replacement processes and further induce considerable additional stresses in the interface body under a temperature change $[24,25]$. To deal with these drawbacks, the single-point mount PZT interface, which uses only one bonded section, has been newly developed [25]. The initial experimental investigation showed that the impedance response of the newlydeveloped interface had strong resonances sensitive to the prestress force [25]. Although the single-point mount PZT interface was successfully tested for anchor force monitoring of a lab-scaled cable-anchorage system, its feasibility should be verified by numerical simulation. Besides, the local dynamic characteristics of the single-point mount PZT interface remain unsolved, and these are difficult to obtain via experimentation. That is, the modal parameters of the smart interface, which are sensitive to the anchor force variation, should be identified to prove the monitoring technique of the anchorage. A reliable numerical model is a further key to optimize the structural and geometrical parameters of the smart interface.

In this study, we therefore conduct the numerical simulation of a single-point mount PZT interface mounted on a prestressed anchorage for admittance-based anchor force monitoring. The study aims to identify the vibration characteristics of the interface that are sensitive to the anchor force. The subsequent parts of the study are organized as follows. The second section outlines the admittance-based technique through a single-mount PZT interface, including the design of an interface prototype and the proof-of-concept of the technique for anchor force monitoring. The next section describes the numerical simulation of the previous experimental model of the PZT interface-anchorage system in literature [25], 
and then compares the numerical admittance response with the experimental data. The fourth section investigates the local dynamic responses of the PZT interface and verifies the numerical feasibility of the admittance-based anchor force monitoring technique. A summary and conclusion of this study are presented in the final section.

\section{Admittance-Based Anchor Force Monitoring Method}

\subsection{Prototype of Single-Point Mount PZT Interface}

Figure 1A illustrates a prototype design of the single-point mount PZT interface, which is a plate-like structure with a bonded part and a flexural part. The PZT interface is attached to a host structure (i.e., an anchorage) via the bonded part while the flexural part is designed to enable convenient vibrations of the PZT due to the piezoelectric effects. This flexural section allows it to produce strong admittance responses. The structural and geometrical parameters of the flexural section can be adjusted to control the damage-sensitive frequency band $[12,14]$. In a typical way, the PZT is excited by a harmonic voltage in a high-frequency band (often in ultrasonic bands) and the admittance signature is measured using an impedance analyzer, as shown in Figure 1B. During the piezoelectric excitation, the interface interacts with the host structure and its coupling responses are represented in the measured admittance signature [24]. Once the host structure is damaged, those coupling responses are shifted, resulting in the change in the admittance signature. By quantifying the change in the admittance signature, the structural damage is feasibly detected.

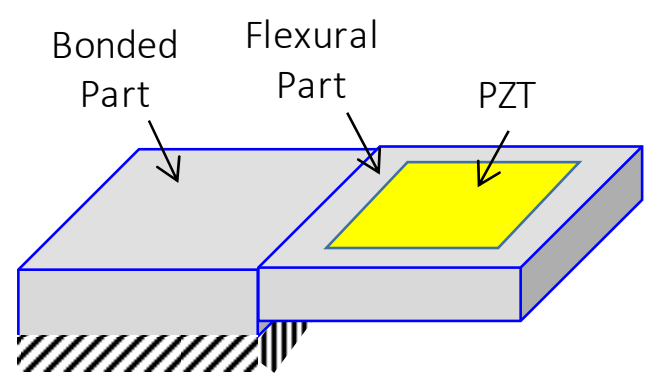

(a)

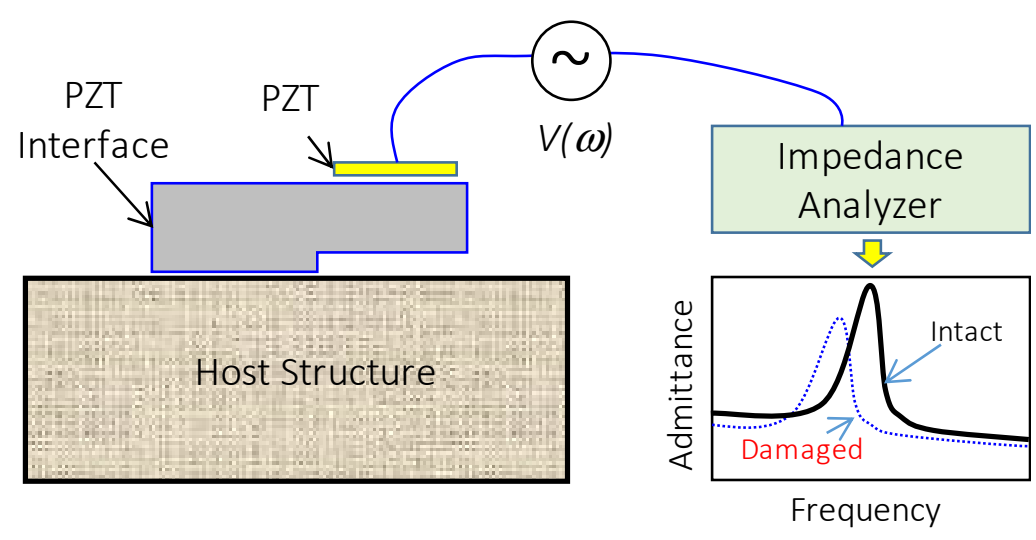

(b)

Figure 1. Admittance monitoring technique using a single-point mount PZT interface. (a) Prototype; (b) Admittance measurement process.

\subsection{Admittance Signature of Single-Point Mount PZT Interface}

The admittance signature of the PZT interface-anchorage system can be theoretically derived using an analytical model in which the PZT patch, the interface, and the anchorage are coupled in a 1-dimensional system [26]. As shown in Figure 2, the interface is simplified by the mass $m_{i}$, the spring $k_{i}$, and the damper $c_{i}$, while the anchorage is represented by the mass $m_{s}$, the spring $k_{s}$, and the damper $c_{s}$.

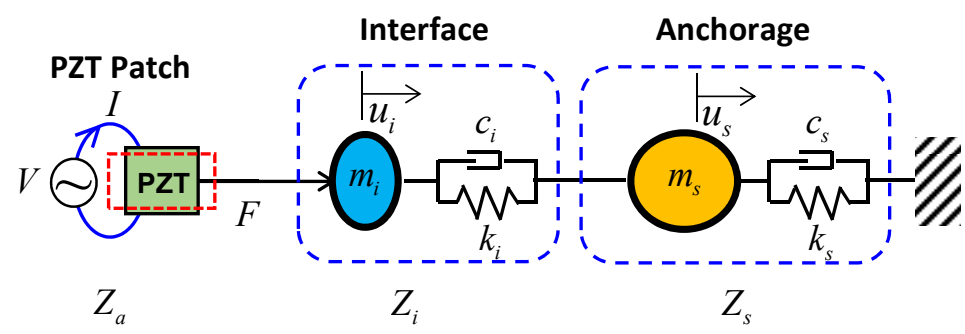

Figure 2. Analytical impedance model of a PZT interface-anchorage interactive system. 
To obtain the admittance of the system, a harmonic voltage $V$ is applied to the PZT patch and makes it expand following the inverse piezoelectric effect. The PZT's deformation introduces an exciting force $F$ into the system and an output current $I$ is concurrently obtained from the PZT. The ratio between the output current and the input voltage is computed as the admittance response $Y$ based on the following formula [27,28]:

$$
Y=\left\{j \omega C\left[1-\frac{\bar{Z}}{\bar{Z}+Z_{a}} \frac{d_{31}^{2} \hat{Y}_{11}^{E}}{\hat{\varepsilon}_{33}^{T}} \frac{\tan \left(k l_{a}\right)}{k l_{a}}\right]\right\}
$$

where $C=\hat{\varepsilon}_{33}^{T} w_{a} l_{a} / t_{a}$ is the capacitance of the PZT patch; $w_{a}, l_{a}$, and $t_{a}$ are, respectively, the effective width, length, and thickness of the PZT; $\hat{Y}_{11}^{E}=(1+j \eta) Y_{11}^{E}$ is the complex Young's modulus of the PZT at the constant electric field; $j$ is the imaginary unit; $\eta$ is the structural damping loss factor of the PZT; $\hat{\varepsilon}_{33}^{T}=\varepsilon_{33}^{T}(1-j \delta)$ is the complex dielectric permittivity at the constant stress; $d_{31}$ is the piezoelectric coupling constant at zero stress; $\delta$ is the dielectric loss factor of the PZT; $k=\omega / c$ is the wavenumber of the PZT and $c$ is the wave speed given by $\sqrt{\rho / Y_{11}^{E}} ; \rho$ is the mass density of the PZT. $Z_{a}=\hat{Y}_{11}^{E} w_{a} t_{a} / j \omega l_{a}$ is the mechanical impedance of the PZT patch and $\bar{Z}$ is the equivalent mechanical impedance of the interface-anchorage system.

From the previous study [25], the equivalent mechanical impedance $\bar{Z}$ can be theoretically estimated by:

$$
\bar{Z}=\frac{K_{11}(\omega) K_{22}(\omega)-K_{12}^{2}(\omega)}{i \omega K_{22}(\omega)}
$$

where $K_{11}, K_{12}$, and $K_{22}$ are the dynamic stiffness terms and are obtained by:

$$
\left[\begin{array}{ll}
K_{11}(\omega) & K_{12}(\omega) \\
K_{12}(\omega) & K_{22}(\omega)
\end{array}\right]=\left[\begin{array}{cc}
-\omega^{2} m_{i}+i \omega c_{i}+k_{i} & -i \omega c_{i}-k_{i} \\
-i \omega c_{i}-k_{i} & -\omega^{2} m_{s}+i \omega\left(c_{i}+c_{s}\right)+\left(k_{i}+k_{s}\right)
\end{array}\right]
$$

By substituting Equation (2) in Equation (1), we can obtain the final equation to calculate the admittance response of the PZT interface-host structure system, as follows:

$$
Y=\left\{i \omega \frac{w_{a} l_{a}}{t_{a}}\left[\hat{\varepsilon}_{33}^{T}-\frac{1}{Z_{a}(\omega) /\left(\frac{K_{11}(\omega) K_{22}(\omega)-K_{12}^{2}(\omega)}{i \omega K_{22}(\omega)}\right)+1} d_{3 x}^{2} \hat{Y}_{x x}^{E}\right]\right\}
$$

Equation (4) shows that the measured admittance consists of the mechanical parameters of both the anchorage and the smart interface. Once the anchorage is damaged (for example, the anchor force is reduced), its structural parameters are varied, resulting in the change in the measured admittance signature. By observing the admittance change, it is feasible to detect the structural damage of the anchorage (i.e., the anchor force change).

\subsection{Anchor Force Monitoring Approach Using Admittance Signature}

To quantify the change in the admittance signature, statistical damage indices such as root-mean-square-deviation (RMSD) and cross-correlation deviation (CCD) are commonly employed [6,29]. The RMSD index measures the difference in the magnitudes of the two admittance signatures as follows [30,31]:

$$
\operatorname{RMSD}\left(Y, Y^{*}\right)=\sqrt{\sum_{i=1}^{N}\left[Y^{*}\left(\omega_{i}\right)-Y\left(\omega_{i}\right)\right]^{2} / \sum_{i=1}^{N}\left[Y\left(\omega_{i}\right)\right]^{2}}
$$

in which $Y\left(\omega_{i}\right)$ and $Y^{*}\left(\omega_{i}\right)$ are the admittance signals of the reference (i.e., the case of initial anchor force) and unknown state (i.e., the case of anchor force change), respectively; the term $N$ is the number of swept frequency points; $\omega_{i}$ is the $i$ th swept frequency. 
The CCD index measures the shift in the pattern of two admittance signatures and is computed by [32].

$$
\operatorname{CCD}\left(Y, Y^{*}\right)=1-\frac{1}{\sigma_{Y} \sigma_{Y}^{*}} E\left\{\left[Y\left(\omega_{i}\right)-\bar{Y}\right]\left[Y^{*}\left(\omega_{i}\right)-\bar{Y}^{*}\right]\right\}
$$

in which $\mathrm{E}[$.$] is the expectation operation; \bar{Y}$ and $\sigma_{Y}$ are the mean and the standard deviation of the admittance signal at the reference state; $\bar{Y}^{*}$ and $\sigma_{Y}^{*}$ are the mean and the standard deviation of the admittance signal at an unknown state. Theoretically, the RMSD and CCD indices are equal to 0 if there is no change in the anchor force, whereas they are higher than 0 when the anchor force is reduced/increased.

\section{Numerical Simulation}

\subsection{Finite Element Model of Single-Point Mount PZT Interface on Prestressed Anchorage}

In the previous study [25], impedance monitoring via a single-point mount PZT interface was conducted on a lab-scale prestressed anchorage. Figure 3 illustrates the overall experimental methodology. At first, a prototype of the single-point mount PZT interface was fabricated and surface-mounted on the bearing plate of the anchorage. Afterwards, the impedance/admittance response was acquired from the PZT interface using an impedance analyzer (HIOKI-3532). A set of anchor forces ( $\mathrm{T}=5,4,3$, and 2 tons) were simulated for the lab-scale anchorage, and the change in the impedance response is monitored to detect the change in the prestressed force. More information about the experimental setup and the anchor force monitoring results can be found in [25].


Figure 3. Overall experimental methodology.

Based on the geometric parameters (see Figure $4 \mathrm{a}$ ) of the experimental model in reference [25], we have established a corresponding numerical model in the finite element modeling program, COMSOL Multiphysics (see Figure 4b). The modeling of the piezoelectric effects of a PZT-driven system requires the coupling between mechanical and electrical physics [33-35]. Due to its strong simulation capacity of the piezoelectric effects, COMSOL was successful to simulate the admittance response of various PZT-driven models [19,35-40]. We therefore employed the COMSOL program to verify the numerical feasibility of the single-point mount PZT interface for anchor force monitoring.

The dimensions of the finite element model are selected to be the same as the dimensions of the experimental model. The model consists of a prestressed tendon-anchorage equipped with a single-point mount PZT interface. An adhesive layer between the PZT interface and the anchorage was also simulated to mimic the experimental model. Based on the previous studies [41-43], the effect of the anchor force can be simulated by a spring and dashpot system. The change in the anchor force is represented by the reduction in the contact stiffness of the spring.

The finite element model was meshed using the user-controlled mesh sequence type available in the simulation program. We progressively increased the number of elements (i.e., a finer mesh) until the admittance response of the model was nearly unchanged. Figure $4 \mathrm{c}$ shows the final meshing of the finite element model. The total number of 
elements was 1654, including 870 prism elements and 784 hexahedral elements. It is noted that finer meshings were imposed to the PZT patch and the interface to accurately simulate the admittance responses and capture their local dynamics.

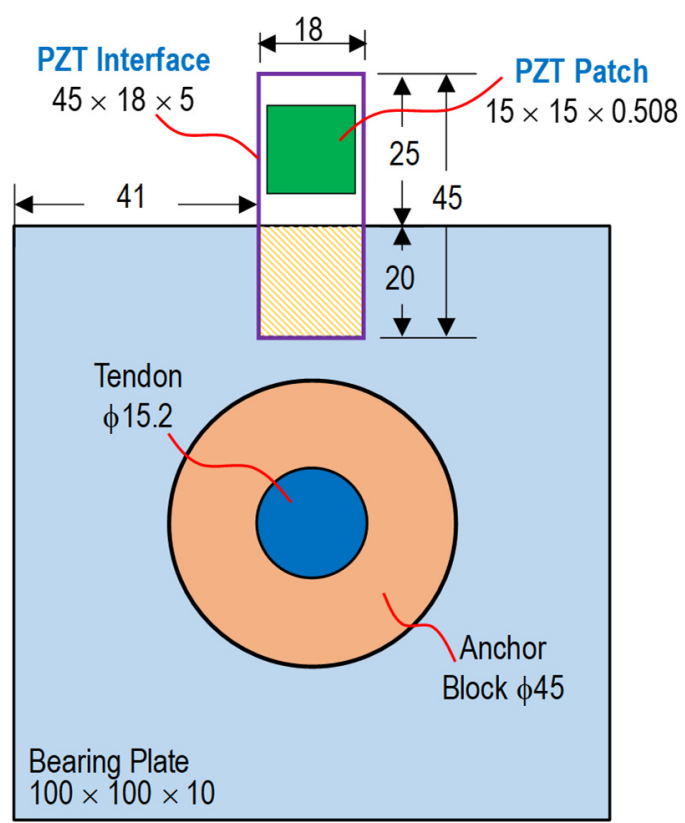

(a)

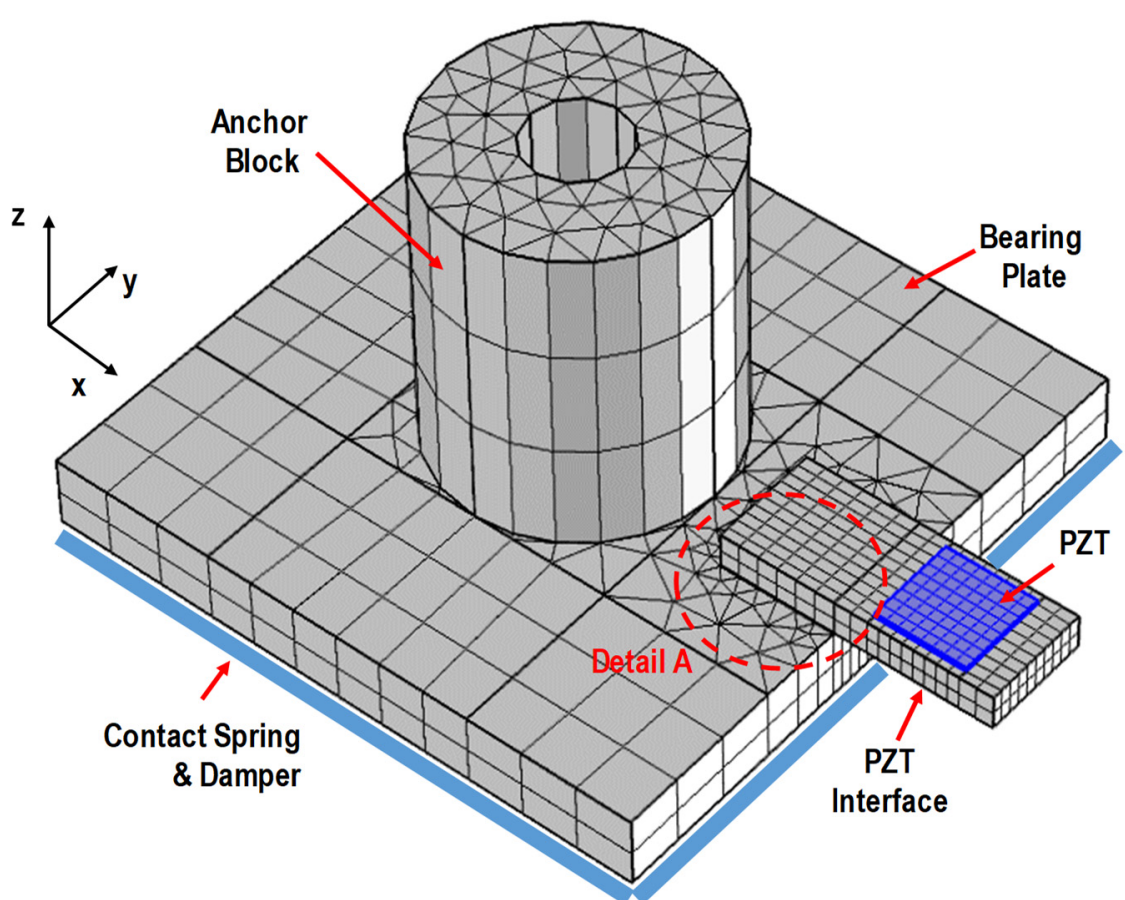

(c)

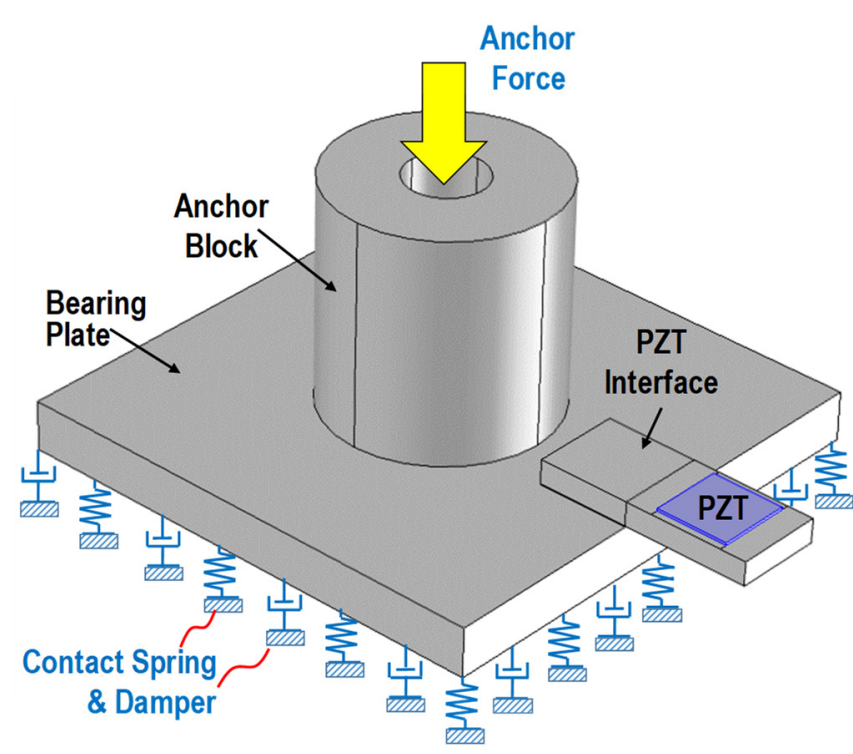

(b)
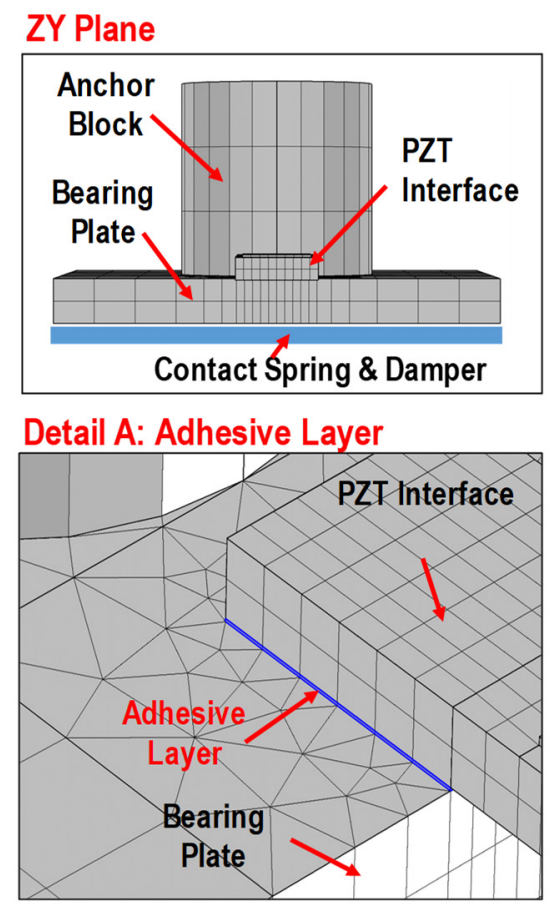

Figure 4. Finite element modelling of the PZT interface-anchorage system. (a) Geometric parameters (unit: mm); (b) Equivalent finite element model; (c) Meshed finite element model.

The mechanical properties of the interface body and its adhesive layer, the anchor block, and the bearing plate are shown in Table 1. The steel anchor head and the bearing plate were assumed to have a Young's modulus of $200 \mathrm{GPa}$, a Poisson's ratio of 0.33 , and a mass density of $7850 \mathrm{~kg} / \mathrm{m}^{3}$ [43]. The aluminum interface was assumed to have a Young's modulus of $70 \mathrm{GPa}$, a Poisson's ratio of 0.33 , and a mass density of $2700 \mathrm{~kg} / \mathrm{m}^{3}$ [43]. Based 
on the previous studies [44-46], the adhesive layer was supposed to have a thickness of $0.2 \mathrm{~mm}$, a Young's modulus of $3 \mathrm{GPa}$, a Poisson's ratio of 0.38 , and a mass density of 1700 $\mathrm{kg} / \mathrm{m}^{3}$. The damping plays a major role in validating the experimental result. Therefore, we carefully selected the damping ratios so that the obtained numerical signature was consistent with the experimental data. Consequently, the damping ratio was selected as $0.5 \%$ for the interface and its adhesive layer and $1 \%$ for the anchor head and the bearing plate. The selected damping ratios were within a reasonable range, according to the references $[40,47]$.

Table 1. Mechanical properties of the aluminum interface and the steel anchorage.

\begin{tabular}{cccc}
\hline Parameters & $\begin{array}{c}\text { Steel Anchor Head and } \\
\text { Bearing Plate }\end{array}$ & Aluminum Interface & Adhesive Layer \\
\hline Young's modulus $(\mathrm{GPa})$ & 200 & 70 & 3 \\
Poisson's ratio & 0.33 & 0.33 & 0.38 \\
Mass density $\left(\mathrm{kg} / \mathrm{m}^{3}\right)$ & 7850 & 2700 & 1700 \\
Damping ratio & 0.01 & 0.005 & 0.005 \\
\hline
\end{tabular}

The PZT patch was assigned by the PZT-5A piezoelectric material (the same as the one used in the previous experiment [25]). The mechanical and piezoelectric properties of the PZT-5A patch were referred to in the previous publication, as listed in Table 2 [43]. The stiffness parameters were manually selected so that the numerical admittance signature was well-agreed with the experimental data. As the result, we identified the contact stiffness as follows: $k_{z}=4 \times 10^{12} \mathrm{~N} / \mathrm{m}^{2} / \mathrm{m}$ and $k_{x}=k_{y}=2 \times 10^{12} \mathrm{~N} / \mathrm{m}^{2} / \mathrm{m}$, which were relatively similar to those obtained from the previous study [43]. The damper system was supposed to have the damping loss factor in the three axes as $\eta_{x}=\eta_{y}=\eta_{z}=2 \%$.

Table 2. Piezoelectric properties of the PZT-5A patch.

\begin{tabular}{|c|c|c|c|c|c|c|c|}
\hline Parameters & \multicolumn{6}{|c|}{ Value } & \\
\hline Elastic compliance $\left(\mathrm{m}^{2} / \mathrm{N}\right)$ & $\begin{array}{c}16.4 \\
-5.74 \\
-7.22 \\
0 \\
0 \\
0\end{array}$ & $\begin{array}{c}-5.74 \\
16.4 \\
-7.22 \\
0 \\
0 \\
0\end{array}$ & $\begin{array}{c}-7.22 \\
-7.22 \\
18.8 \\
0 \\
0 \\
0 \\
10^{-}\end{array}$ & $\begin{array}{c}0 \\
0 \\
0 \\
47.5 \\
0 \\
12\end{array}$ & $\begin{array}{c}0 \\
0 \\
0 \\
0 \\
47.5 \\
0\end{array}$ & $\left.\begin{array}{c}0 \\
0 \\
0 \\
0 \\
0 \\
44.3\end{array}\right)$ & $x$ \\
\hline Dielectric coupling constant $(\mathrm{C} / \mathrm{N})$ & & $\begin{array}{c}0 \\
0 \\
0 \\
0 \\
584 \\
0 \\
\end{array}$ & $\begin{array}{cc}0 & - \\
0 & - \\
0 & 3 \\
584 & \\
0 & \\
0 & \\
\end{array}$ & $\left.\begin{array}{l}171 \\
171 \\
74 \\
0 \\
0 \\
0\end{array}\right)$ & $\times 10^{-1}$ & & \\
\hline Permittivity (Farad/m) & $\left(\begin{array}{c}1730 \\
0 \\
0\end{array}\right.$ & $\begin{array}{c}0 \\
1730 \\
0\end{array}$ & $\begin{array}{c}0 \\
0 \\
1700\end{array}$ & $\times(8$ & $8.854 \times$ & $\left.10^{-12}\right)$ & \\
\hline Mass density $\left(\mathrm{kg} / \mathrm{m}^{3}\right)$ & \multicolumn{7}{|c|}{7750} \\
\hline Damping loss factor & \multicolumn{7}{|c|}{0.005} \\
\hline Dielectric loss factor, $\delta$ & \multicolumn{7}{|c|}{0.015} \\
\hline
\end{tabular}

\subsection{Numerical Admittance Response vs. Experimental Result}

To obtain the numerical admittance from the finite element model, we simulated the same experimental conditions by applying a harmonic voltage of $1 \mathrm{~V}$ to the top surface of the PZT patch while the ground electrode was imposed to the bottom surface. The sweep frequency band was $10-100 \mathrm{kHz}$ with an interval of $0.18 \mathrm{kHz}$ (i.e., 501 frequency 
points). At each swept frequency, the governing equations of the problem were solved by the generalized minimum residual (GMRES) iterative method. The convergence error of the simulation was defined as 0.001 . The admittance response was computed as the ratio between the output current from the PZT patch and the input voltage applied on it.

The real part of the numerical impedance signature is compared with the experimental data (the case of $\mathrm{T}=5$ tons) [25] in Figure $5 \mathrm{a}$. Similar to the experimental result, we observed three strong resonant bands (i.e., $20-35 \mathrm{kHz}, 70-80 \mathrm{kHz}$, and $90-95 \mathrm{kHz}$ ) in the frequency range of 10-100 kHz. Specifically, four strong resonant peaks (i.e., Peak 1-Peak 4) were observed in the numerical data; those were identical to the peaks of the experimental result. We also observed identical patterns between the numerical simulation and the experiment at non-resonant bands (i.e., $10-20 \mathrm{kHz}, 35-70 \mathrm{kHz}, 80-90 \mathrm{kHz}$, and $95-100 \mathrm{kHz}$ ).

The imaginary part of the numerical impedance signature was also well-agreed with the experimental signature, as shown in Figure $5 b$. It should be noted that the imaginary part mainly contains the information of the PZT patch. Thus, the good agreement between the imaginary impedance signatures suggested that the piezoelectric effects of the PZT patch were well simulated by COMSOL. The resultant admittance signatures were compared between the simulating model and the experimental model in Figure 5c. It is shown that the trend, the magnitude, and the resonant bands of the two models were identical.

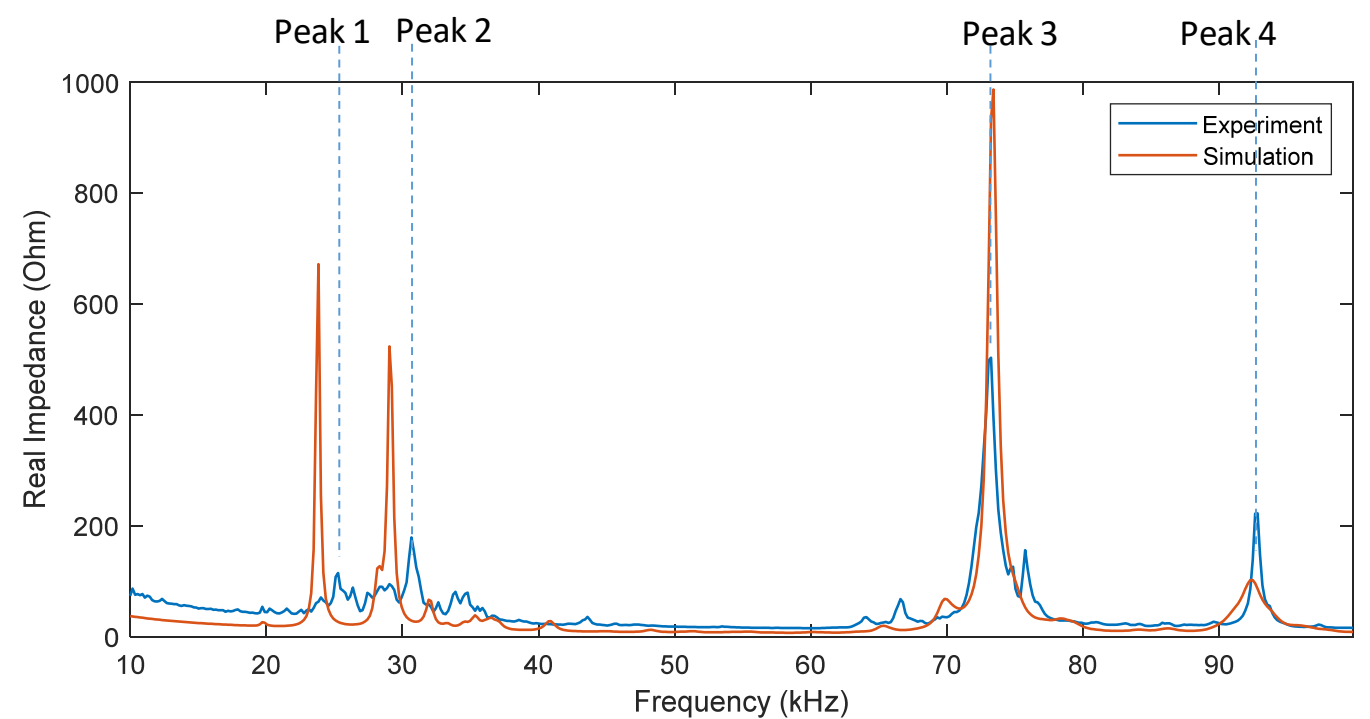

(a)

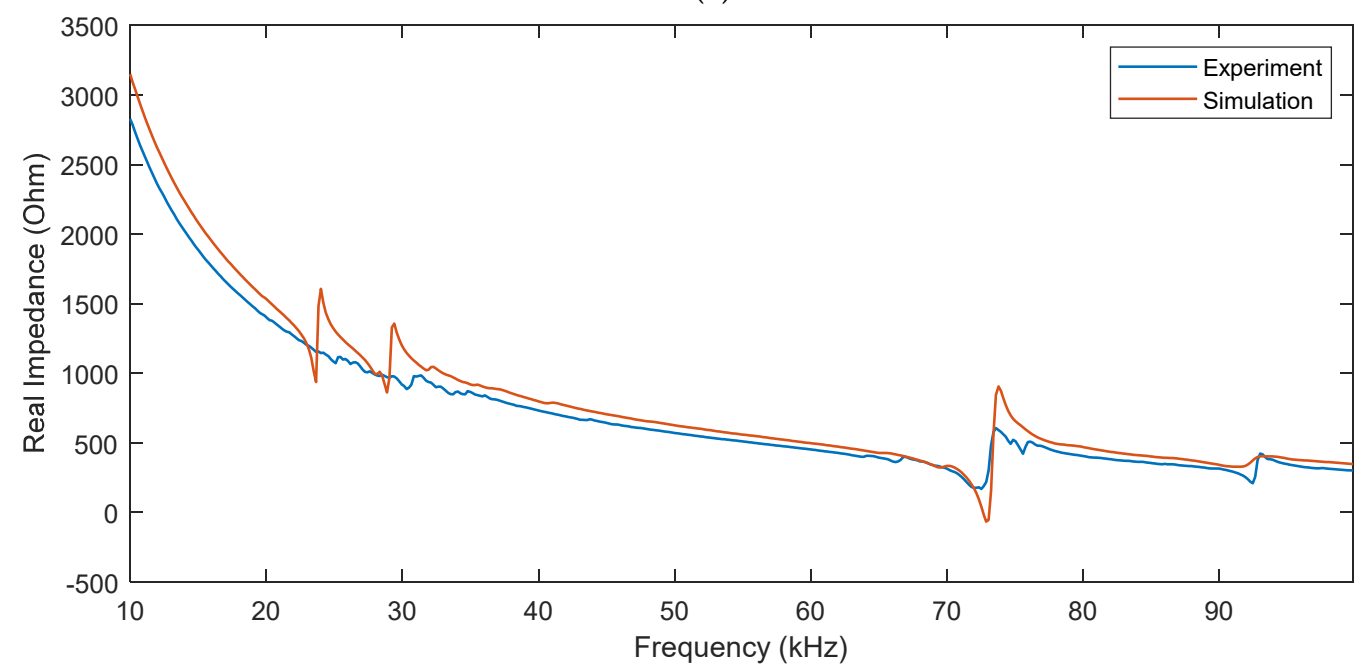

(b)

Figure 5. Cont. 


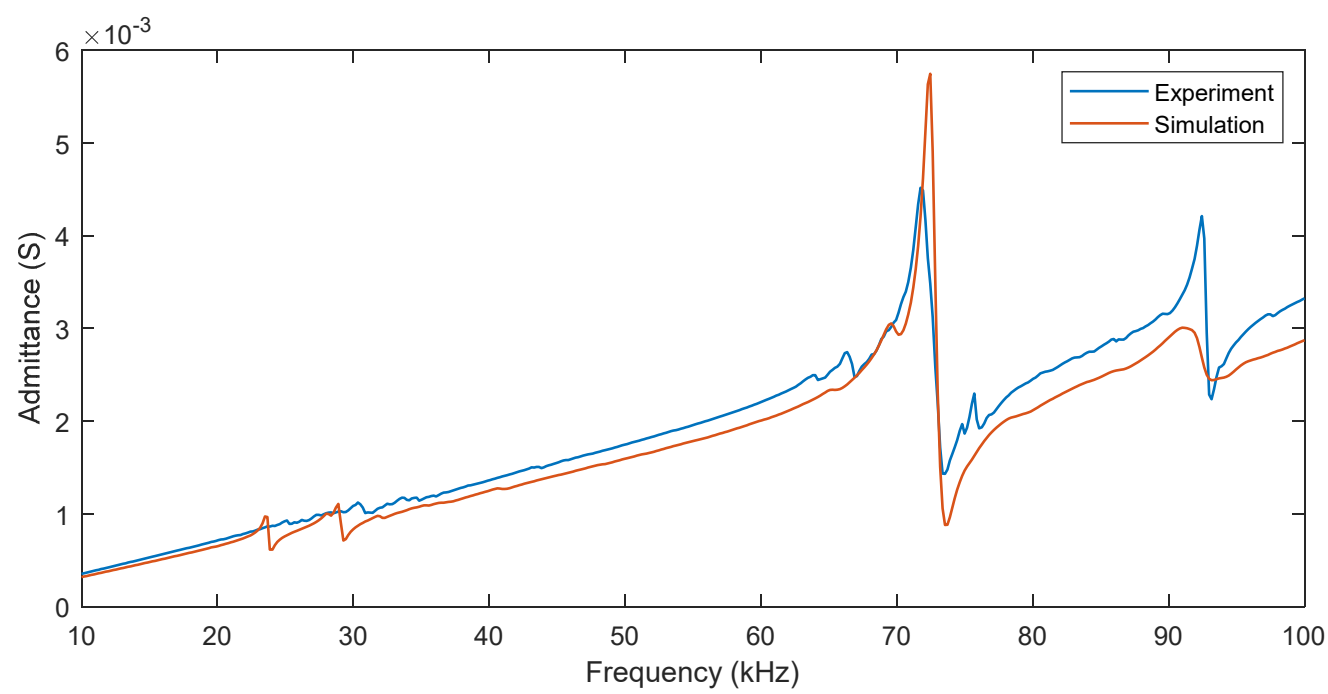

(c)

Figure 5. Comparison of impedance responses between the simulation and the experiment. (a) Real impedance signatures; (b) Imaginary impedance signatures; (c) Admittance signatures.

The frequency of the four peaks observed in the numerical impedance signature is compared with the experimental result in Figure 6 and is listed in Table 3. It is seen that the peak frequencies showed good agreements between the two models. In this study, we used the peak frequency values for calculating the error between the experimental and simulation results. The maximum frequency error was only $5.69 \%$ (Peak 1 ) and the minimum error was ignorable at $0.24 \%$ (Peak 3 ). It is noted that the frequency of the vertical bending modes (Peak 1 and Peak 2 ) is strongly dependent on the vertical bending stiffness of the flexural part of the PZT interface. The error is relatively higher for Peak 1 and Peak 2 due to the difference in the vertical bending stiffness between the finite element model and the experimental model. To narrow this gap, it is necessary to update the structural parameters (e.g., elastic modulus) that affect the vertical bending stiffness of the flexural part of the interface [46]. Despite that, the finite element model was successful to predict the experimental admittance response in the literature [25].

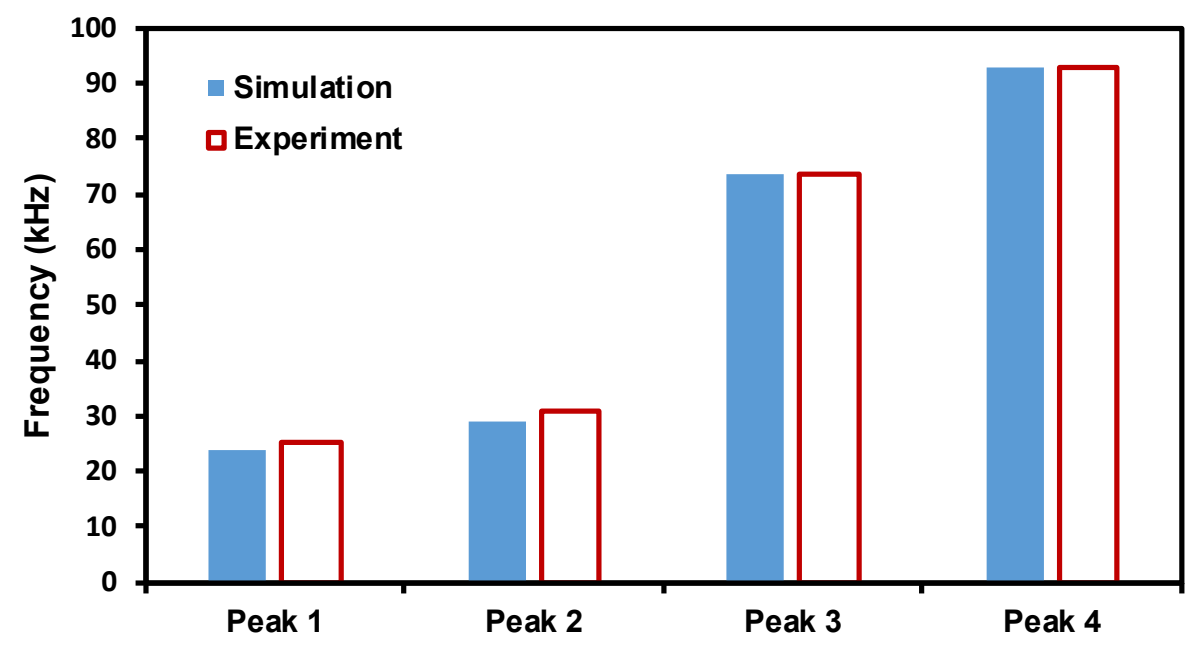

Figure 6. Comparison of peak frequencies between the numerical simulation and the experiment. 
Table 3. The frequency of the impedance peaks.

\begin{tabular}{ccccc}
\hline Peak & $\begin{array}{c}\text { Simulation } \\
\mathbf{( k H z )}\end{array}$ & $\begin{array}{c}\text { Experiment } \\
\mathbf{( k H z )}\end{array}$ & $\begin{array}{c}\text { Difference } \\
\mathbf{( k H z )}\end{array}$ & Error (\%) \\
\hline 1 & 23.86 & 25.3 & -1.44 & 5.69 \\
2 & 29.08 & 30.7 & -1.62 & 5.28 \\
3 & 73.54 & 73.36 & 0.18 & 0.24 \\
4 & 92.62 & 92.98 & -0.36 & 0.39 \\
\hline
\end{tabular}

\section{Dynamic Characteristics and Numerical Feasibility Verification}

To demonstrate the numerical feasibility of the single-point mount smart interface for anchor force monitoring, there is a need to identify the local vibration modes of the interface that are identical to the resonant peaks and to prove that the frequency of those modes is changed by the change in the anchor force.

\subsection{Local Dynamic Characteristics of Single-Point Mount PZT Interface}

First, the local dynamic characteristics of the single-point mount smart interface were examined to determine the modal parameters of the resonant impedance peaks that were sensitive to the anchor force change. It is noted from Figure 5a that the numerical impedance signature showed four strong resonant peaks at $23.86 \mathrm{kHz}$ (Peak 1), $29.08 \mathrm{kHz}$ (Peak 2), $73.54 \mathrm{kHz}$ (Peak 3), and $92.62 \mathrm{kHz}$ (Peak 4) in the frequency range of 10-100 kHz. There was, therefore, a need to find the vibration modes of the smart interface for those resonant peaks.

We performed the numerical modal analysis using the established finite element model in COMSOL. Consequently, we identified four vibration modes of the smart interfaceanchorage system that showed identical frequencies with the four impedance peaks, as sketched in Figure 7a. Specifically, the identified mode that occurred at $23.721 \mathrm{kHz}$ belonged to the first impedance peak (Peak 1), while the one that occurred at $29.041 \mathrm{kHz}$ was attributed to the second impedance peak (Peak 2). The mode that occurred at $72.550 \mathrm{kHz}$ was assigned to the third impedance peak (Peak 3), and the one that occurred at $92.724 \mathrm{kHz}$ belonged to the fourth impedance peak (Peak 4).

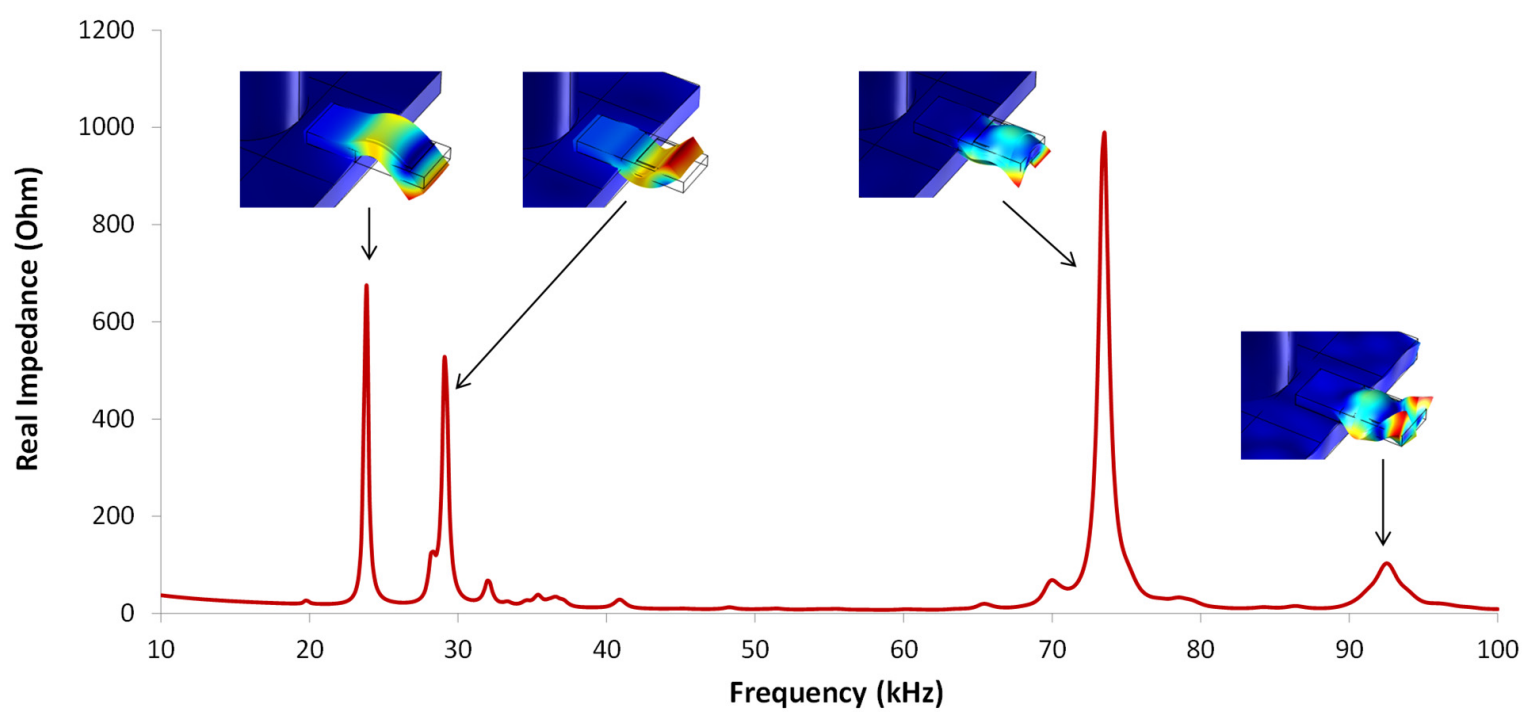

(a)

Figure 7. Cont. 


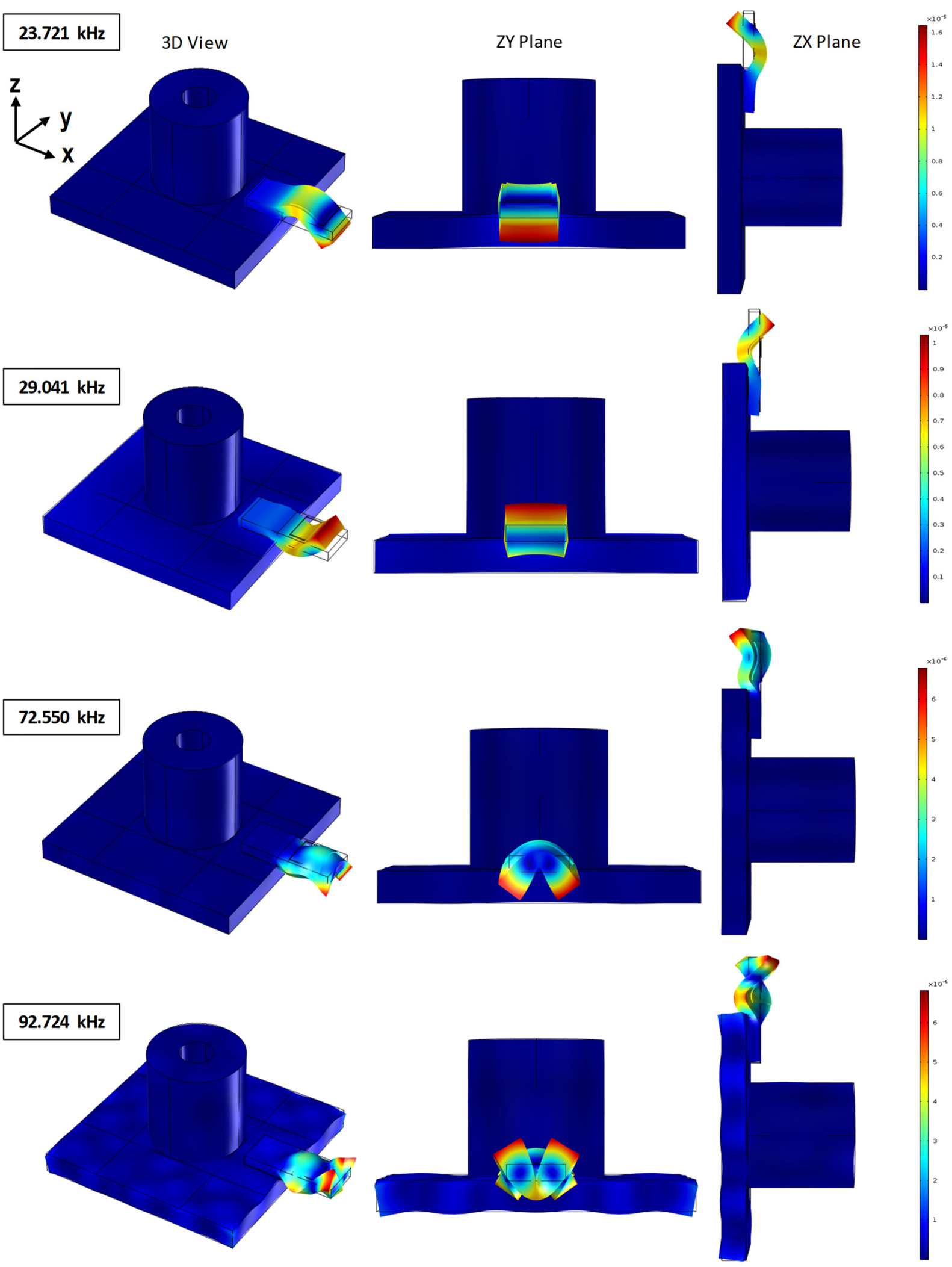

(b)

Figure 7. Identified modal parameters corresponding to resonant impedance peaks of the PZT interface-anchorage system. (a) Identified modes for the resonant impedance peaks; (b) 3-dimensional modal shapes of the identified modes.

The frequency and 3-dimensional modal shapes of the identified modes are depicted in Figure $7 \mathrm{~b}$. It is observed that the first and the second peaks had vertical bending motions 
(translations in the zx plane), while the third and the fourth peaks exhibited coupled vertical-lateral bending motions (translations in both the zx plane and the zy plane). The result suggests that the piezoelectric deformation of the PZT patch mainly excited the bending motions of the interface.

\subsection{Numerical Feasibility of Single-Point Mount PZT Interface for Anchor Force Monitoring}

Next, we proved that the resonant frequency of the identified modes (i.e., the resonant impedance peaks) was changed due to the change in the anchor force. From the explanation in Section 3.1, the effect of the anchor force was treated by the stiffness and damping parameters at the contact interface of the bearing plate. To simulate the change in the anchor force in the finite element model, we reduced the value of the contact stiffness in the three axes $\left(k_{x}, k_{y}, k_{z}\right)$. Four cases of the contact stiffness (i.e., Case 1-Case 4$)$ are detailed in Table 4. That is, Case 1 was the intact case while the contact stiffness was reduced by $25 \%, 50 \%$, and $75 \%$ in Case 2, Case 3, and Case 4, respectively.

Table 4. The peak frequency vs. damage case.

\begin{tabular}{ccccccc}
\hline \multirow{2}{*}{$\begin{array}{c}\text { Damage } \\
\text { Case }\end{array}$} & \multicolumn{2}{c}{$\begin{array}{c}\text { Area Contact Stiffness } \\
\left.\mathbf{( N / m} / \mathbf{m}^{2}\right)\end{array}$} & & \multicolumn{2}{c}{ Peak Frequency $(\mathbf{k H z})$} & \\
\cline { 2 - 7 } & $\boldsymbol{k}_{\boldsymbol{x}}=\boldsymbol{k}_{\boldsymbol{y}}$ & $\boldsymbol{k}_{\boldsymbol{z}}$ & Peak 1 & Peak 2 & Peak 3 & Peak 4 \\
\hline Case 1 & $20 \times 10^{11}$ & $40 \times 10^{11}$ & 23.86 & 29.08 & 73.54 & 92.62 \\
\hline Case 2 & $16 \times 10^{11}$ & $32 \times 10^{11}$ & 23.26 & 28.36 & 73.36 & 92.44 \\
\hline Case 3 & $12 \times 10^{11}$ & $24 \times 10^{11}$ & 22.6 & 28.72 & 73.36 & 92.62 \\
\hline Case 4 & $8 \times 10^{11}$ & $16 \times 10^{11}$ & 20.8 & 27.46 & 73.36 & 92.62 \\
\hline
\end{tabular}

Figure 8 shows the real part of the numerical impedance signatures in the wide frequency band of $10-100 \mathrm{kHz}$ and two strong resonant bands of $20-30 \mathrm{kHz}$ and $70-75$ $\mathrm{kHz}$ for the four damage cases. Similar to the previous experimental results [25], the real impedance signatures showed certain variations under the change in the contact stiffness. The frequency band of $20-30 \mathrm{kHz}$ varied more sensitively than the band of 70-75 $\mathrm{kHz}$. Similar observations were found from the plots of the imaginary impedance and the admittance signatures, as seen in Figures 9 and 10, respectively.

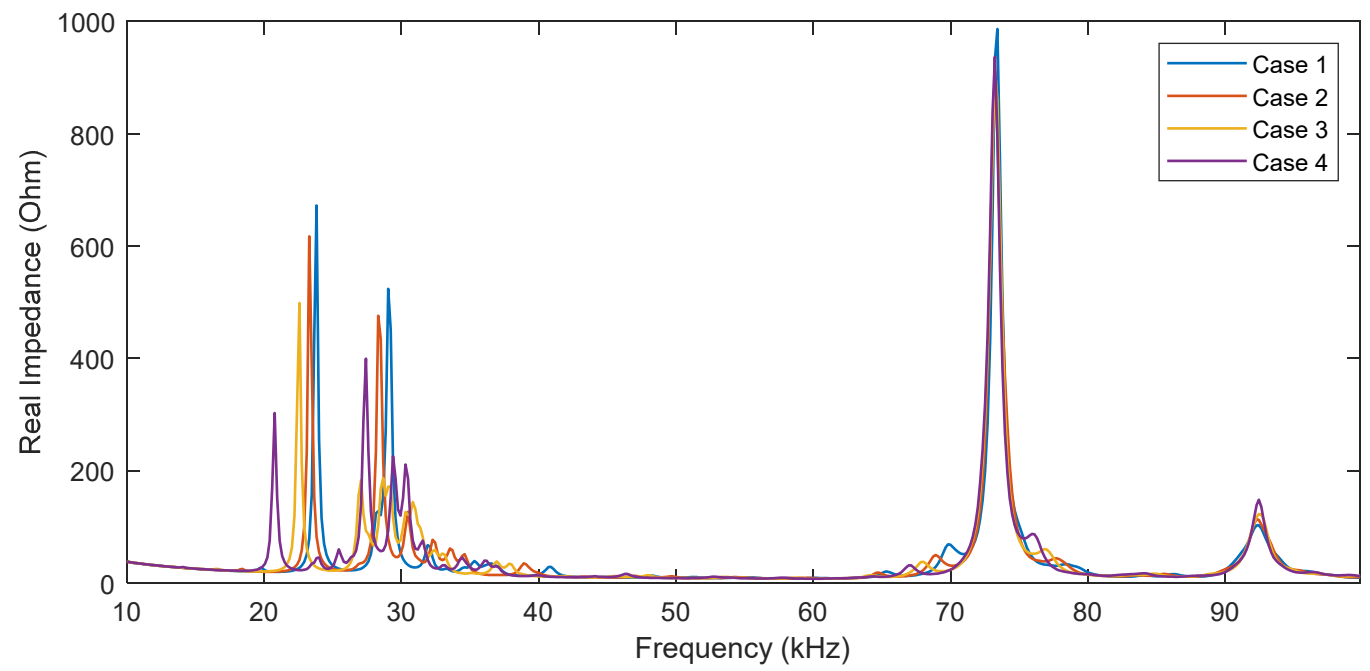

(a)

Figure 8. Cont. 


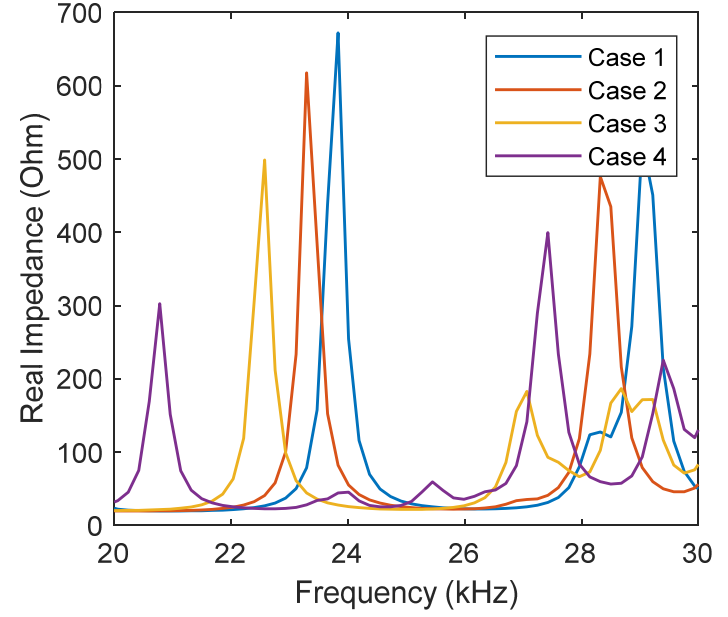

(b)

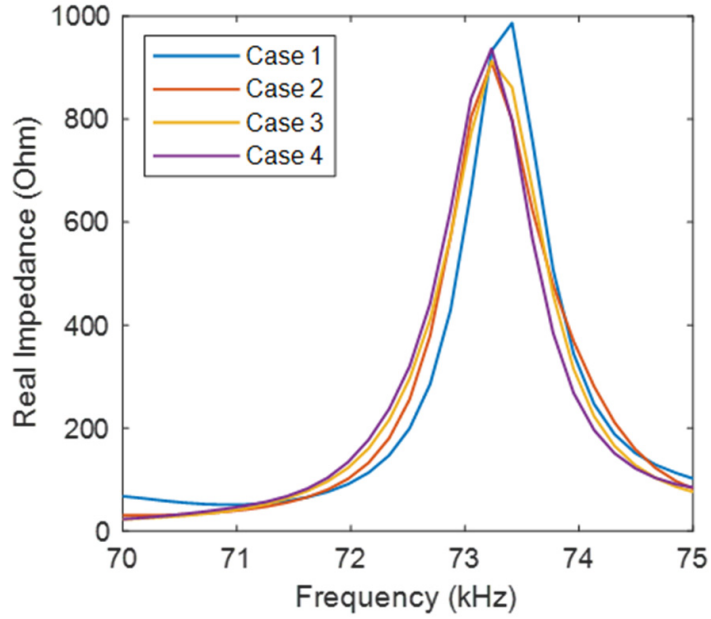

(c)

Figure 8. The real part of the numerical impedance signatures for different cases of contact stiffness. (a) 10-100 kHz; (b) $20-30 \mathrm{kHz}$; (c) $70-75 \mathrm{kHz}$.

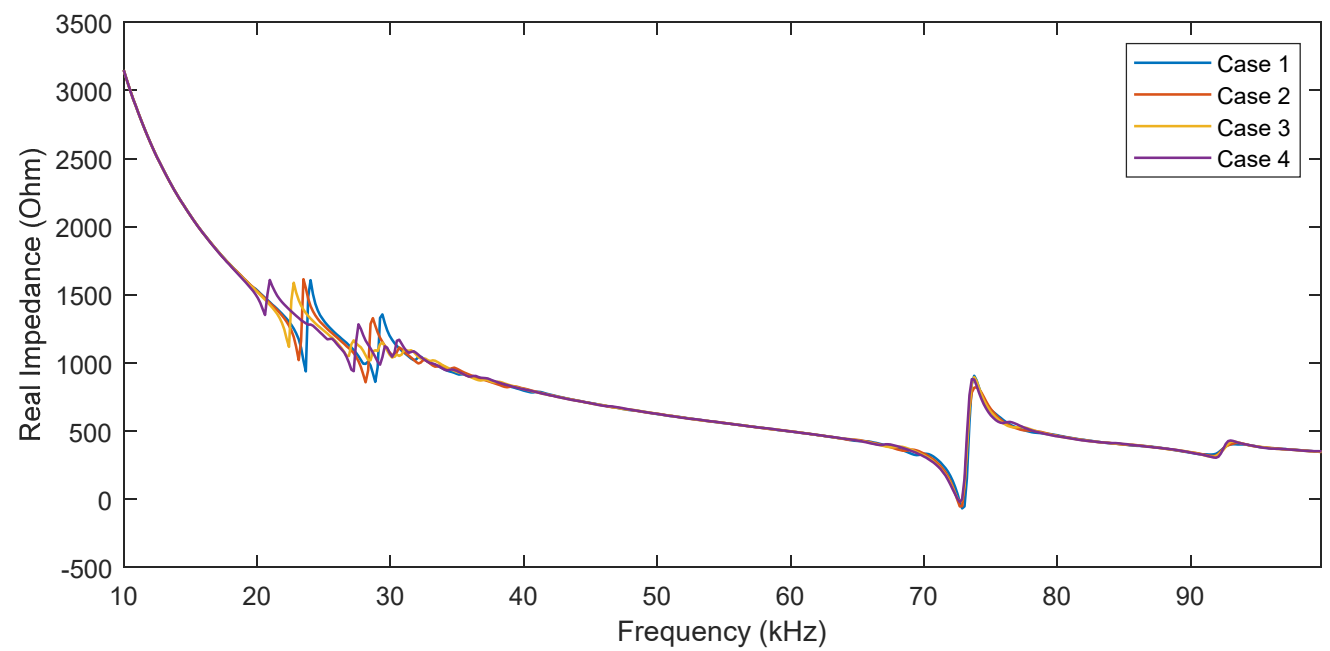

(a)

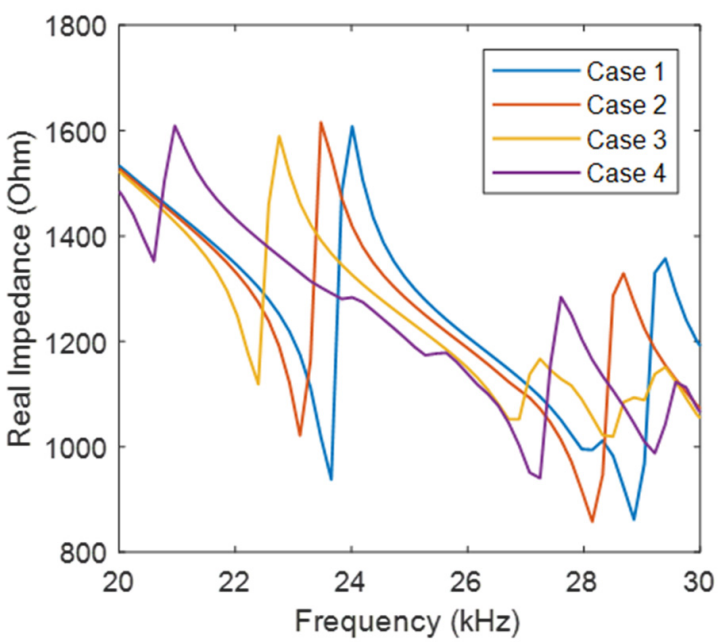

(b)

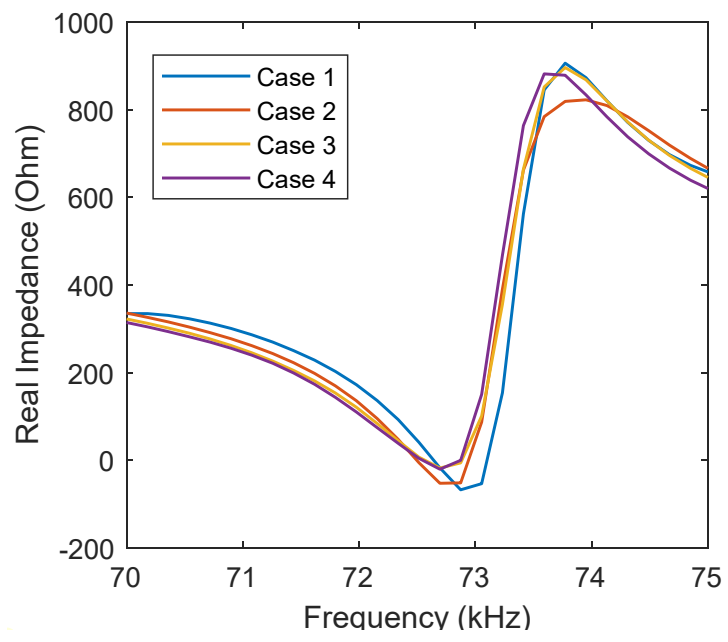

(c)

Figure 9. The imaginary part of the numerical impedance signatures for different cases of contact stiffness. (a) 10-100 kHz; (b) $20-30 \mathrm{kHz}$; (c) $70-75 \mathrm{kHz}$. 


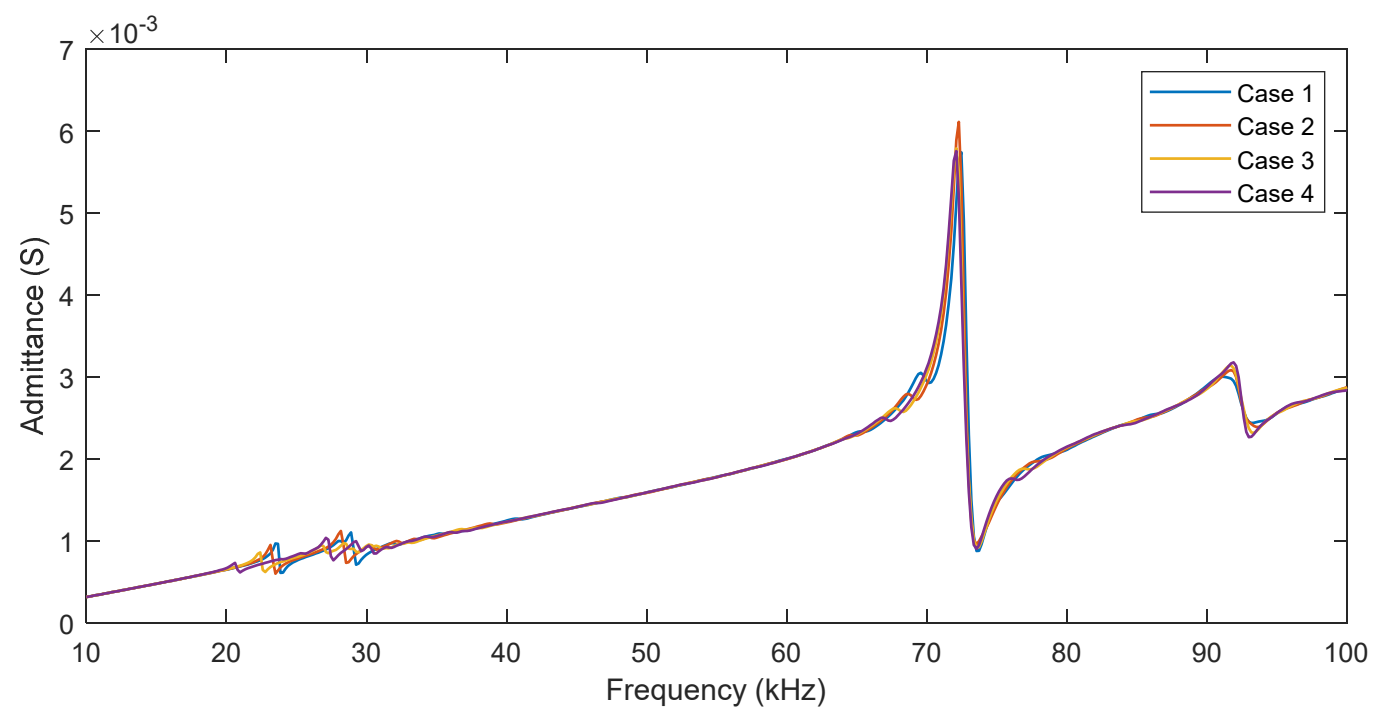

(a)

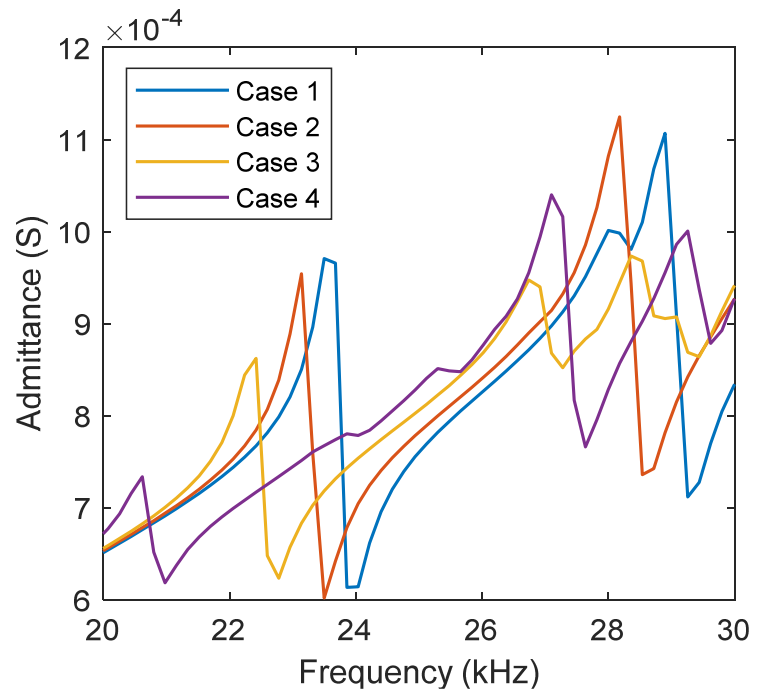

(b)

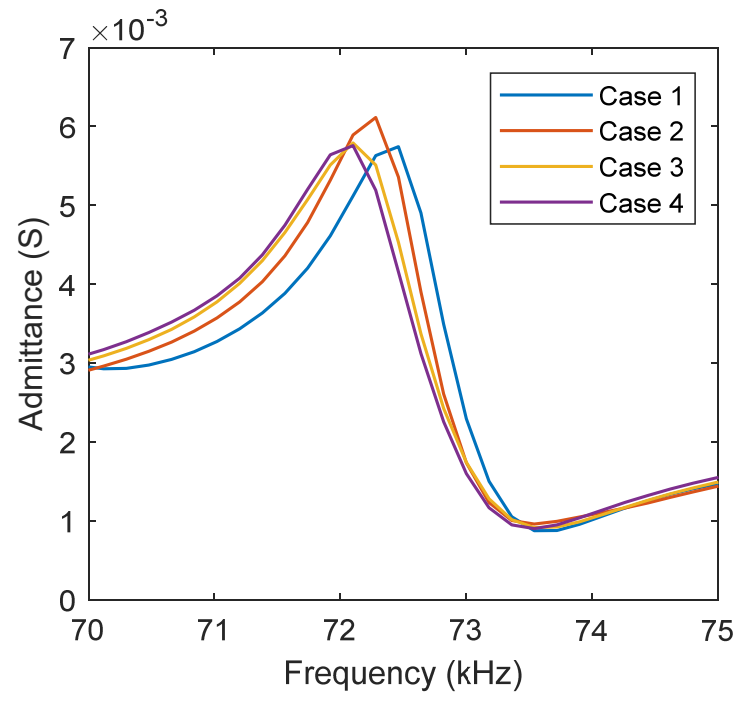

(c)

Figure 10. The numerical admittance signatures for different cases of contact stiffness. (a) $10-100 \mathrm{kHz}$; (b) $20-30 \mathrm{kHz}$; (c) $70-75 \mathrm{kHz}$.

The resonant frequency of the four peaks was extracted, as listed in Table 4 . The peak frequencies tended to reduce as the contact stiffness was lost. The percentage of frequency shift was calculated, as depicted in Figure 11. The frequency shift of Peak 1 was the most significant while that of Peak 2 was moderate and those of Peak 3 and Peak 4 were ignorable. Since the four impedance peaks were associated with the four identified modes of the smart interface (see Figure 7a), it was shown that the frequency of the first and the second identified modes was significantly sensitive to the contact stiffness change (i.e., the anchor force reduction) while those of the remaining modes experienced ignorable changes.

Finally, the damage indices (i.e., RMSD and CCD) were computed using the numerical admittance response. The RMSD and CCD indices for the resonant band of $20-30 \mathrm{kHz}$ are shown in Figure 12a,b, respectively. The damage indices varied with the contact stiffness (i.e., the anchor force). However, strong nonlinearities were observed in the changing trends of both damage indices. There was a drop in the damage indices at Case 3, while the values of Case 2 and Case 4 were quite similar. Therefore, anchor force monitoring using this frequency band could lead to inaccurate diagnosis results. 


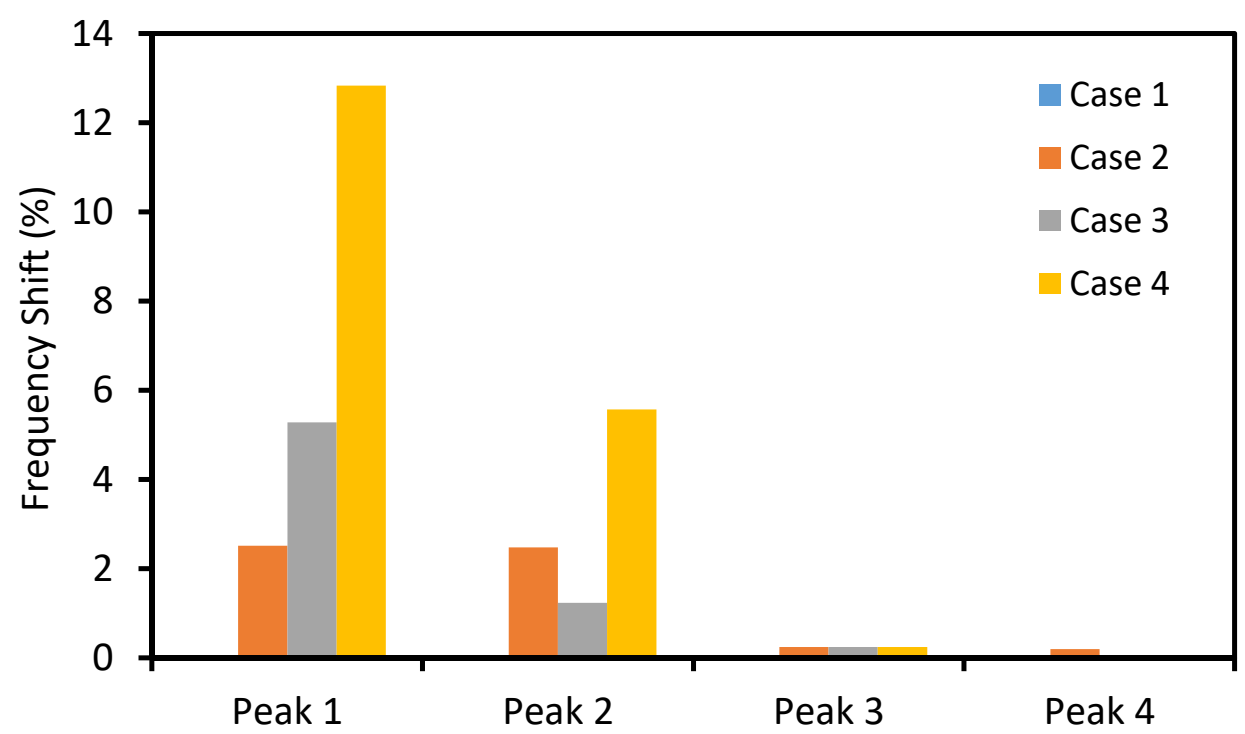

Figure 11. The frequency shift for different cases of contact stiffness.

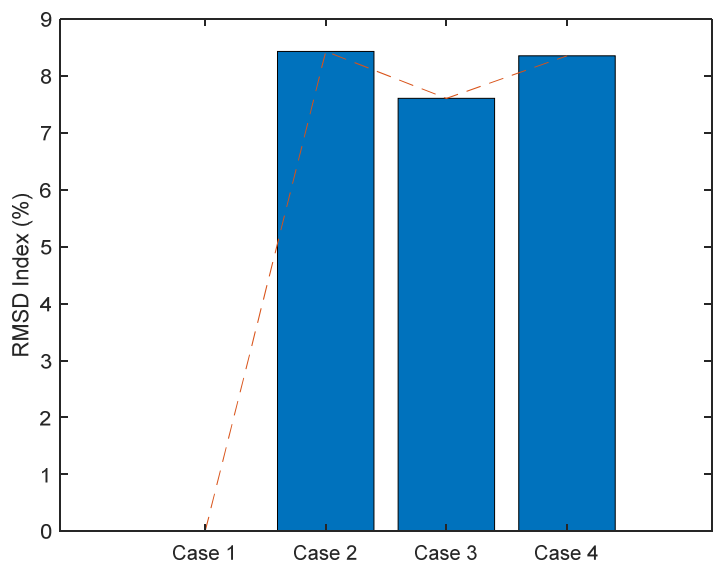

(a)

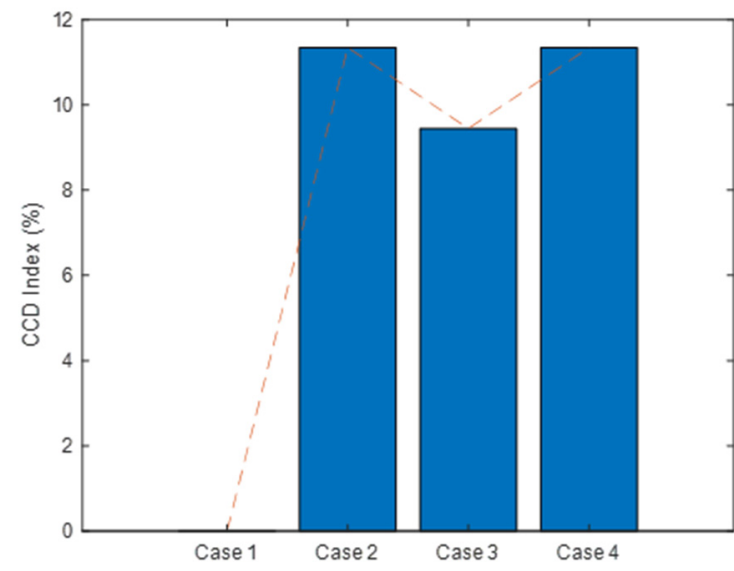

(b)

Figure 12. The damage indices for the frequency range of 20-40 kHz. (a) RMSD index; (b) CCD index.

Figure 13a,b, respectively, show the RMSD and CCD indices for the frequency band of $70-75 \mathrm{kHz}$. In contrast with the frequency band of $20-30 \mathrm{kHz}$, clear changing trends were observed. The RMSD index was proportional with the contact stiffness, but the changing trend was rather nonlinear. Meanwhile, the CCD index exhibited a fairly linear change with the contact stiffness. The result suggests that the anchor force monitoring result was improved when the second resonant band was employed. The numerical observations were well-consistent with the previous experimental results [25], demonstrating the numerical feasibility of the single-point mount PZT interface for anchor force monitoring of the anchorage system.

It is noted that the local vibrations and the admittance of the PZT interface are mainly dependent on the sizes of the PZT patch and the interface body. While the modal frequency of vibration modes strongly varies with the size of the interface body, the size of the PZT determines the curve of the imaginary admittance; the size of the PZT patch should be also large enough to excite the vibration modes of the interface [48]. The sizes of the bearing plate, the anchor block, and the tendon have only minor effects on the local dynamic characteristics of the PZT interface, but they do affect the admittance response of the PZT interface. To sufficiently quantify such geometric effects, a parametric study will be investigated in a future study. 


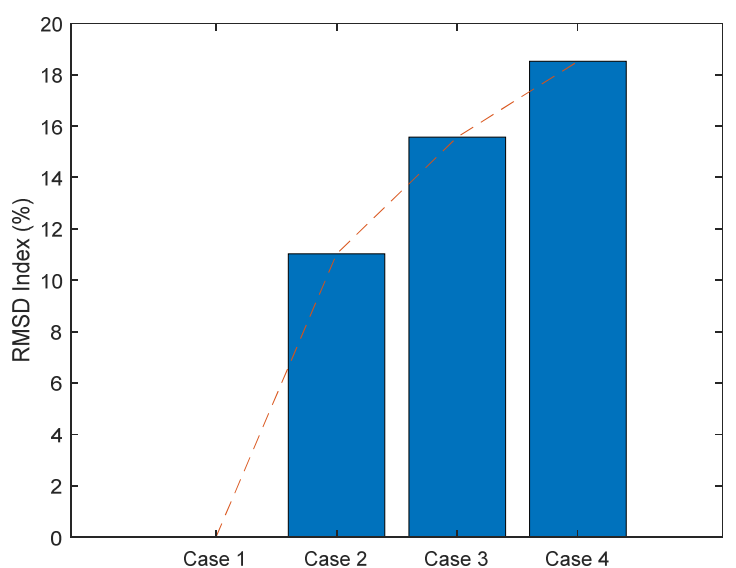

(a)

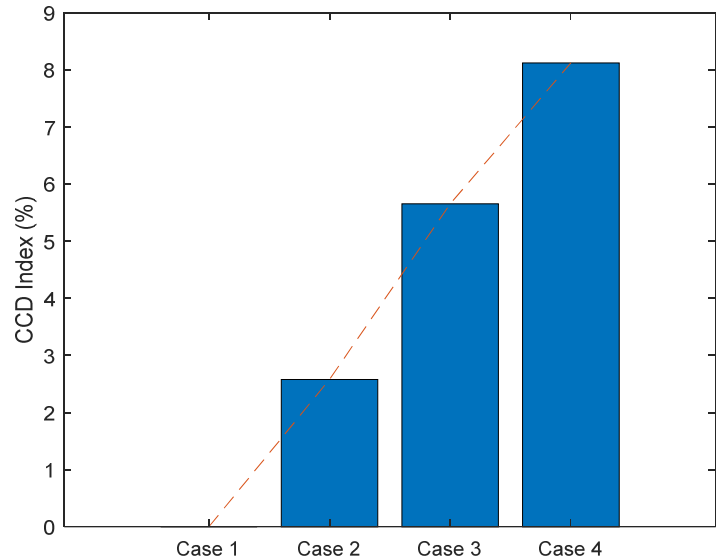

(b)

Figure 13. The damage indices for the frequency range of 70-80 kHz. (a) RMSD index; (b) CCD index.

\section{Summary and Conclusions}

In this work, the numerical modeling and local dynamic characteristics of a singlepoint mount PZT interface on a prestressed anchorage were investigated to show the numerical feasibility of the anchor force monitoring technique. First, the admittance response of the smart interface was theoretically derived from an analytical impedance model to show the proof-of-concept of the technique. Second, finite element modeling of the PZT interface-anchorage system corresponding to the experimental model was conducted. The admittance and impedance responses of the smart interface were analyzed and compared with the experimental data. Fourth, the local dynamics of the PZT interface were analyzed by the modal analysis approach to determine the sensitive vibration modes. Finally, the impedance and admittance responses corresponding to the sensitive vibration modes were numerically analyzed under the change in the anchor force (i.e., the contact stiffness). The frequency shift and the admittance change were quantified to verify the numerical feasibility of the anchor force monitoring technique through the single-point mount smart interface.

From the numerical investigation, the following concluding remarks can be drawn, as follows: (1) The simulated impedance and admittance responses were well-matched with the experimental data in the literature. Thus, the electromechanical response of the single-point mount PZT interface can be reliably predicted by the numerical modeling technique. (2) Four sensitive vibration modes (including two longitudinal bending modes and two longitudinal-lateral hybrid bending modes) that correspond to the four resonant impedance peaks were identified. (3) The impedance and the admittance responses of the identified modes were found to be sensitive to the change in anchor force (i.e., the contact stiffness). Among four modes, the two longitudinal bending modes showed the most frequency variations. (4) Similar to the previous experimental observation, the third vibration mode of the single-point mount PZT interface was found to be suitable for anchor force monitoring. (5) The numerical feasibility of the anchor force monitoring technique through the single-point mount smart interface was successfully verified. The RMSD and CCD damage indices were sensitively varied with the change in the contact stiffness (representing the change in the anchor force). In the resonant band of $70-75 \mathrm{kHz}$, the CCD index showed a fairly linear change with the contact stiffness while the change in the RMSD index was rather nonlinear. The study is expected to provide a reference numerical model for the design of the single-point mount PZT interface.

The future research remains as follows: (1) a parametric study will be investigated to sufficiently quantify the geometric effects on the local dynamic characteristics and the admittance/impedance responses of the PZT interface; (2) our research group is also working 
on updating the damping ratios to get a better agreement in the admittance magnitudes and improving the finite element model to consider the stress effect of the anchor force on the shift of admittance signatures; (3) a quantitative estimation of the admittance-spring stiffness-anchor force relationship will be sufficiently investigated; (4) the authors will explore new applications of the presented technique (e.g., monitoring the axial stress in rock bolts).

Author Contributions: Conceptualization, T.-C.H., D.-D.H. and T.-H.N.; methodology, T.-C.H., D.D.H., T.-H.N. and T.T.V.P.; validation, T.-C.H., D.-D.H., T.-C.L., T.-H.N. and T.T.V.P.; formal analysis, T.-C.H., T.-H.N., D.-D.H., T.-C.L. and T.T.V.P.; writing-original draft preparation, T.-C.H., D.-D.H., T.-H.N. and T.T.V.P.; writing-review and editing, T.-C.H. All authors have read and agreed to the published version of the manuscript.

Funding: This research received no external funding.

Data Availability Statement: The data are available upon request.

Acknowledgments: We acknowledge the support of time and facilities from Ho Chi Minh City University of Technology (HCMUT), VNU-HCM for this study.

Conflicts of Interest: The authors declare no conflict of interest.

\section{References}

1. Yang, Y.; Hu, Y.; Lu, Y. Sensitivity of PZT Impedance Sensors for Damage Detection of Concrete Structures. Sensors 2008, 8 , 327-346. [CrossRef]

2. Yang, W.; Yang, X.; Li, S. Monitoring of Interfacial Debonding of Concrete Filled Pultrusion-GFRP Tubular Column Based on Piezoelectric Smart Aggregate and Wavelet Analysis. Sensors 2020, 20, 2149. [CrossRef] [PubMed]

3. Na, W.S.; Baek, J. A Review of the Piezoelectric Electromechanical Impedance Based Structural Health Monitoring Technique for Engineering Structures. Sensors 2018, 18, 1307. [CrossRef]

4. Huynh, T.-C.; Kim, J.-T. RBFN-based temperature compensation method for impedance monitoring in prestressed tendon anchorage. Struct. Control Health Monit. 2018, 25, e2173. [CrossRef]

5. Negi, P.; Chakraborty, T.; Bhalla, S. Viability of electro-mechanical impedance technique for monitoring damage in rocks under cyclic loading. Acta Geotech. 2021, 1-13. [CrossRef]

6. Park, G.; Inman, D.J. Impedance-Based Structural Health Monitoring. In Damage Prognosis for Aerospace, Civil and Mechanical Systems; Wiley: Hoboken, NJ, USA, 2005. [CrossRef]

7. Tseng, K.K.; Wang, L. Impedance-Based Method for Nondestructive Damage Identification. J. Eng. Mech. 2005, 131, 58-64. [CrossRef]

8. Huynh, T.-C.; Lee, S.-Y.; Dang, N.-L.; Kim, J.-T. Sensing Region Characteristics of Smart Piezoelectric Interface for Damage Monitoring in Plate-Like Structures. Sensors 2019, 19, 1377. [CrossRef]

9. Kim, J.-T.; Park, J.-H.; Hong, D.-S.; Park, W.-S. Hybrid health monitoring of prestressed concrete girder bridges by sequential vibration-impedance approaches. Eng. Struct. 2010, 32, 115-128. [CrossRef]

10. Min, J.; Park, S.; Yun, C.-B. Impedance-based structural health monitoring using neural networks for autonomous frequency range selection. Smart Mater. Struct. 2010, 19, 125011. [CrossRef]

11. Park, S.; Shin, H.-H.; Yun, C.-B. Wireless impedance sensor nodes for functions of structural damage identification and sensor self-diagnosis. Smart Mater. Struct. 2009, 18, 055001. [CrossRef]

12. Park, J.-H.; Kim, J.-T.; Hong, D.-S.; Mascarenas, D.; Lynch, J.P. Autonomous smart sensor nodes for global and local damage detection of prestressed concrete bridges based on accelerations and impedance measurements. Smart Struct. Syst. 2010, 6, 711-730. [CrossRef]

13. Nguyen, K.-D.; Kim, J.-T. Smart PZT-interface for wireless impedance-based prestress-loss monitoring in tendon-anchorage connection. Smart Struct. Syst. 2012, 9, 489-504. [CrossRef]

14. Perera, R.; Pérez, A.; García-Diéguez, M.; Zapico-Valle, J.L. Active Wireless System for Structural Health Monitoring Applications. Sensors 2017, 17, 2880. [CrossRef]

15. Yan, S.; Sun, W.; Song, G.; Gu, H.; Huo, L.-S.; Liu, B.; Zhang, Y.-G. Health monitoring of reinforced concrete shear walls using smart aggregates. Smart Mater. Struct. 2009, 18, 047001. [CrossRef]

16. Song, G.; Gu, H.; Mo, Y.-L. Smart aggregates: Multi-functional sensors for concrete structures-A tutorial and a review. Smart Mater. Struct. 2008, 17, 033001. [CrossRef]

17. Fan, S.; Zhao, S.; Kong, Q.; Song, G. An embeddable spherical smart aggregate for monitoring concrete hydration in very early age based on electromechanical impedance method. J. Intell. Mater. Syst. Struct. 2021, 32, 537-548. [CrossRef] 
18. Le, T.-C.; Phan, T.T.V.; Nguyen, T.-H.; Ho, D.-D.; Huynh, T.-C. A Low-Cost Prestress Monitoring Method for Post-Tensioned RC Beam Using Piezoelectric-Based Smart Strand. Buildings 2021, 11, 431. [CrossRef]

19. Ryu, J.-Y.; Huynh, T.-C.; Kim, J.-T. Tension Force Estimation in Axially Loaded Members Using Wearable Piezoelectric Interface Technique. Sensors 2019, 19, 47. [CrossRef] [PubMed]

20. Li, W.; Liu, T.; Zou, D.; Wang, J.; Yi, T.-H. PZT based smart corrosion coupon using electromechanical impedance. Mech. Syst. Signal Process. 2019, 129, 455-469. [CrossRef]

21. Nguyen, K.-D.; Lee, S.-Y.; Lee, P.-Y.; Kim, J.-T. Wireless SHM for bolted connections via multiple PZT-interfaces and Imote2platformed impedance sensor node. In Proceedings of the 6ANCRiSST, Dalian, China, 25-26 July 2011.

22. Huynh, T.-C.; Kim, J.-T. Impedance-Based Cable Force Monitoring in Tendon-Anchorage Using Portable PZT-Interface Technique. Math. Probl. Eng. 2014, 2014, 784731. [CrossRef]

23. Dang, N.; Huynh, T.; Pham, Q.; Lee, S.; Kim, J. Damage-sensitive impedance sensor placement on multi-strand anchorage based on local stress variation analysis. Struct. Control Health Monit. 2020, 27, 2547. [CrossRef]

24. Huynh, T.-C.T.; Kim, J.-T. Quantification of temperature effect on impedance monitoring via PZT interface for prestressed tendon anchorage. Smart Mater. Struct. 2017, 26, 125004. [CrossRef]

25. Le, T.-C.; Ho, D.-D.; Huynh, T.-C. Anchor Force Monitoring Using Impedance Technique with Single-Point Mount Lead-ZirconateTitanate Interface: A Feasibility Study. Buildings 2021, 11, 382. [CrossRef]

26. Huynh, T.-C.; Kim, J.-T. Quantitative damage identification in tendon anchorage via PZT interface-based impedance monitoring technique. Smart Struct. Syst. 2017, 20, 181-195.

27. Liang, C.; Sun, F.P.; Rogers, C.A. Coupled Electro-Mechanical Analysis of Adaptive Material Systems-Determination of the Actuator Power Consumption and System Energy Transfer. J. Intell. Mater. Syst. Struct. 1994, 5, 12-20. [CrossRef]

28. Xu, Y.G.; Liu, G.R. A Modified Electro-Mechanical Impedance Model of Piezoelectric Actuator-Sensors for Debonding Detection of Composite Patches. J. Intell. Mater. Syst. Struct. 2002, 13, 389-396. [CrossRef]

29. Yang, Y.; Liu, H.; Annamdas, V.G.M.; Soh, C.K. Monitoring damage propagation using PZT impedance transducers. Smart Mater. Struct. 2009, 18, 045003. [CrossRef]

30. Sun, F.P.; Chaudhry, Z.; Liang, C.; Rogers, C.A. Truss Structure Integrity Identification Using PZT Sensor-Actuator. J. Intell. Mater. Syst. Struct. 1995, 6, 134-139. [CrossRef]

31. Saravanan, T.J.; Balamonica, K.; Priya, C.B.; Gopalakrishnan, N.; Murthy, S.G.N. Piezoelectric EMI-Based Monitoring of Early Strength Gain in Concrete and Damage Detection in Structural Components. J. Infrastruct. Syst. 2017, 23, 04017029. [CrossRef]

32. Zagrai, A.N.; Giurgiutiu, V. Electro-Mechanical Impedance Method for Crack Detection in Thin Plates. J. Intell. Mater. Syst. Struct. 2001, 12, 709-718. [CrossRef]

33. Uddin, N.; Islam, S.; Sampe, J.; Ali, S.H.M.; Bhuyan, M. Design and simulation of piezoelectric cantilever beam based on mechanical vibration for energy harvesting application. In Proceedings of the 2016 International Conference on Innovations in Science, Engineering and Technology (ICISET), Dhaka, Bangladesh, 28-29 October 2016; pp. 1-4.

34. Bin Mansoor, M.; Köble, S.; Wong, T.W.; Woias, P.; Goldschmidtböing, F. Design, Characterization and Sensitivity Analysis of a Piezoelectric Ceramic/Metal Composite Transducer. Micromachines 2017, 8, 271. [CrossRef]

35. Dang, N.-L.; Huynh, T.-C.; Kim, J.-T. Local Strand-Breakage Detection in Multi-Strand Anchorage System Using an ImpedanceBased Stress Monitoring Method-Feasibility Study. Sensors 2019, 19, 1054. [CrossRef] [PubMed]

36. Kim, J.-T.; Nguyen, K.-D.; Park, J.-H. Wireless Impedance Sensor Node and Interface Washer for Damage Monitoring in Structural Connections. Adv. Struct. Eng. 2012, 15, 871-885. [CrossRef]

37. Huynh, T.-C. Structural parameter identification of a bolted connection embedded with a piezoelectric interface. Vietnam J. Mech. 2020, 42, 173-188. [CrossRef]

38. Nguyen, T.-T.; Kim, J.-T.; Ta, Q.-B.; Ho, D.-D.; Phan, T.T.V.; Huynh, T.-C. Deep learning-based functional assessment of piezoelectric-based smart interface under various degradations. Smart Struct. Syst. 2021, 28, 69-87.

39. Negi, P.; Chakraborty, T. Preliminary Experimental and Numerical Studies on PZT Patch and Rock Interaction: EMI Approach; Springer: Singapore, 2021; pp. 627-636.

40. Huynh, T.-C.; Dang, N.-L.; Kim, J.-T. Preload Monitoring in Bolted Connection Using Piezoelectric-Based Smart Interface. Sensors 2018, 18, 2766. [CrossRef] [PubMed]

41. Johnson, K.L. Contact Mechanics; Cambridge University Press: Cambridge, UK, 1985. [CrossRef]

42. Ritdumrongkul, S.; Abe, M.; Fujino, Y.; Miyashita, T. Quantitative health monitoring of bolted joints using a piezoceramic actuator-sensor. Smart Mater. Struct. 2003, 13, 20-29. [CrossRef]

43. Huynh, T.-C.; Park, Y.-H.; Park, J.-H.; Kim, J.-T. Feasibility Verification of Mountable PZT-Interface for Impedance Monitoring in Tendon-Anchorage. Shock Vib. 2015, 2015, 262975. [CrossRef]

44. Ong, C.W.; Yang, Y.; Wong, Y.T.; Bhalla, S.; Lu, Y.; Soh, C.K. Effects of adhesive on the electromechanical response of a piezoceramictransducer-coupled smart system. In Proceedings of the Smart Materials, Structures, and Systems, Bangalore, India, 14 October 2003; pp. 241-247.

45. Gresil, M.; Yu, L.; Giurgiutiu, V.; Sutton, M. Predictive modeling of electromechanical impedance spectroscopy for composite materials. Struct. Health Monit. 2012, 11, 671-683. [CrossRef] 
46. Nguyen, B.-P.; Tran, Q.H.; Nguyen, T.-T.; Pradhan, A.M.S.; Huynh, T.-C. Understanding Impedance Response Characteristics of a Piezoelectric-Based Smart Interface Subjected to Functional Degradations. Complexity 2021, 2021, 1-24. [CrossRef]

47. Cremer, L.; Heckl, M.; Petersson, B.A.T. Damping. In Structure-Borne Sound: Structural Vibrations and Sound Radiation at Audio Frequencies; Springer: Berlin/Heidelberg, Germany, 2005; pp. 149-235. [CrossRef]

48. Huynh, T.-C.; Ho, D.-D.; Dang, N.-L.; Kim, J.-T. Sensitivity of Piezoelectric-Based Smart Interfaces to Structural Damage in Bolted Connections. Sensors 2019, 19, 3670. [CrossRef] [PubMed] 